Revista de Estudios Histórico-Jurídicos

[Sección Historia de los Derechos Patrios de América]

XXXIII (Valparaíso, Chile, 2011)

[pp. 511 - 532]

\title{
PARTICIPACIÓN DE LA POBLACIÓN INDÍGENA \\ de Arica y Tarapacá EN LA POLÍTICA Y La JUSTICIA COMUNITARIAS DURANTE EL SIGLO XIX
}

["Participation of the Indigenous People of Arica and Tarapacá in Politics and in the Community Form of Justice During the $19^{\text {th }}$ Century"]

\author{
Alberto Díaz Araya* \\ RodRIGO RuZ ZaGAL ${ }^{* *}$ \\ Luis GaLdames Rosas***
}

\begin{abstract}
RESUMEN
Este artículo analiza la participación de los indígenas andinos de Arica y Tarapacá en los sistemas políticos y judiciales a nivel comunitario durante la República peruana (siglo XIX). Sobre la base de información documental, se discute cómo los indígenas articulan localmente la participación política y la administración de la justicia al asumir cargos civiles (alcaldes, jueces de paz, entre otros), como miembros activos de una ciudadanía regional en permanente construcción.
\end{abstract}

Palabras clave

Política - Justicia - sociedad andina ciudadanía - Arica - Tarapacá.

\section{Abstract}

This article analyzes the participation of the Arica and Tarapacá indigenous people in the political and legal systems, at a community level, during the Peruvian Republic (19 ${ }^{\text {th }}$ century). Based on documentary information, we discuss how the native people, locally articulate the political participation and the administration of justice when taking on civil positions (mayors, justice of peace, among others), as active members of a regional citizenship under permanent construction.

\section{Keywords}

Politics, Justice, Andean society, citizenship, Arica, Tarapacá

RECIBIDO el 9 de julio y ACEPTADO el 7 de julio de 2011

* Universidad de Tarapacá, Departamento de Ciencias Históricas y Geográficas. Dirección postal: Av. 18 de septiembre 2222, Arica. Correo electrónico: albertodiaz@uta.cl

** Universidad de Tarapacá, Departamento de Ciencias Históricas y Geográficas. Dirección postal: Av. 18 de septiembre 2222, Arica. Correo electrónico: rruz@uta.cl

*** Universidad de Tarapacá, Departamento de Ciencias Históricas y Geográficas. Dirección postal: Av. 18 de septiembre 2222, Arica. Correo electrónico: lgaldame@uta.cl 


\section{INTRODUCCIÓN****}

El advenimiento del siglo XIX trajo consigo varias novedades para las sociedades indígenas andinas de Arica y Tarapacá. Una de ellas consistió en la reestructuración del sistema burocrático hispano a partir de la Constitución de Cádiz de 1812. Esta fecha fue significativa pues a partir de ella es posible plantear la soberanía popular y los proyectos cívicos propuestos por los ciudadanos, en un intento por asumir compromisos políticos y de identidad a favor de una naciente comunidad nacional que se erige en las postrimeras del virreinato peruano ${ }^{1}$. En el plano político, Cádiz permitía, dentro un espíritu liberal, la participación de todos los miembros del Estado en las prácticas democráticas dispuestas particularmente en programas electorales (incluso de los analfabetos), situación que generó diversos debates en torno a los segmentos indios y mestizos del antiguo Perú, quienes, bajo el nuevo formato legal, tenían en efecto derecho a voto como ciudadanos y, de hecho, participaron activamente en los comicios de los ayuntamientos ${ }^{2}$.

Sin embargo, este panorama de participación política de los indígenas sufrió un giro inesperado. Una vez instalada la república peruana, fue necesario aclarar el rol político de los indígenas en ella: ya sea como ciudadanos o como indios. Bajo el influjo del liberalismo que alimentó el ideario emancipador, los indios fueron considerados como huellas de un pasado turbulento y políticamente incivilizado $^{3}$. En el nuevo contexto republicano, la idea era hablar de ciudadanos y no de indios, bajo los principios de igualdad universal y la fraternidad entre las castas coloniales dentro del discurso ilustrado decimonónico. La lógica que motivada a los libertadores era que en un escenario republicano donde teóricamente moraban ciudadanos, no deberían existir los “indios”. No obstante, la realidad andina, como argumenta Thurner ${ }^{4}$, dictaba lo contrario, debido a que la presencia de los “indios" impedía la consolidación de la incipiente república, lo que significó que éstos fueran invisibilizados en términos de aspirar a un status privilegiado al interior de la comunidad nacional peruana. Entonces, ¿cómo es posible advertir la praxis política de los indígenas, si éstos no eran considerados

\footnotetext{
**** ABREVIATURAS: ADT = Archivo Departamental de Tacna; AGN = Archivo General de la Nación, Perú; AJA = Archivo Nacional de Chile, Archivos Judiciales de Arica; AJI = Archivo Nacional de Chile, Archivos Judiciales de Iquique; APT = Archivo Nacional de Chile, Archivo de la Prefectura de Tarapacá; BNP = Biblioteca Nacional del Perú.

${ }^{1}$ Aljovín De Losada, Cristóbal, Prácticas políticas y formación de ciudadanía, en ChilePerú, Perú-Chile: 1820-1920. Desarrollos políticos, económicos y culturales (Valparaíso, Ediciones Universitarias de Valparaíso, 2005). Para fines analíticos, consignemos que el actual norte chileno donde se insertan las comunidades indígenas andinas de Arica y Tarapacá, pertenecieron hasta la segunda mitad del siglo XIX a la República del Perú. Tras la guerra del Pacífico (1879 - 1883) el Estado chileno asume la administración del territorio como parte de la zona septentrional del país.

${ }^{2}$ Guarisco, Claudia, Etnicidad y ciudadanía en México y Perú (1770-1850), en Documentos de Investigación del Colegio Mexiquense, 84 (México, 2004).

${ }^{3}$ ThURNer, Mark, Los indios y la repúblicas entre 1830-1880, en Historia de América Andina, Creación de las repúblicas y formación de la nación (Quito, Universidad Andina Simón Bolívar, 2003), V, p. 176.

${ }^{4}$ Ibíd.
} 
ciudadanos con derecho a voto? ¿Cómo se politizan las comunidades andinas surperuanas según las normativas imperantes durante el siglo XIX? ¿Cuáles son los mecanismos de articulación local que los indígenas utilizaron como construcción de una ciudadanía política en el Perú en términos de la infrapolítica al interior de las comunidades durante el siglo XIX?

Es necesario advertir que este es un debate reciente entre los investigadores que estudian la experiencia ciudadana y política de las poblaciones andinas 5 . Las versiones tradicionales exponen que los indígenas no participaron de los sistemas políticos ni de los procesos electorales en el Perú como lo cuestiona Aljovín de Losada $^{6}$. En los mismos parámetros de este debate, Chiaramonti ${ }^{7}$ y Núñez ${ }^{8}$ han demostrado que los indígenas peruanos poseían un alto compromiso político y una cultura electoral desde la época colonial tardía. Núñez, estudiando la Constitución de Cádiz, analiza el comportamiento de los indígenas en las elecciones de ayuntamiento entre 1812 y 1814 , y enfatiza la presencia de un gran número de indios sufragantes en las localidades serranas; de hecho, la zona andina exhibió el porcentaje más alto del electorado peruano ${ }^{9}$. De la misma forma, Chiaramonti ${ }^{10}$ presenta varios casos de indígenas que resultaron electos en los ayuntamientos. Particularmente, describe el caso del pueblo de Puquina localizado en el departamento de Moquegua en los altos de Tacna, donde un indio fue elegido alcalde en 1813 pese a los reclamos de los vecinos españoles, los cuales expusieron al intendente atemorizados la posibilidad de que un indio alcanzara "la Judicatura y el Gobierno en los Pueblos donde los Españoles residen"11. Al parecer, el acceso a ocupar algunos cargos de representación ciudadana fue una realidad para los indios durante los primeros años del siglo XIX. En 1822 se estipuló que todos los "peruanos" (hombres), mayores de edad, casados, que no sean vagos y supieran

${ }^{5}$ Díaz, Alberto, De la cordillera al mar. Una reflexión histórica sobre los aymaras chilenos y los mercados regionales, en Boletin International Fellowship Program. Leadership for Social Justice Institute, 2 (2004) 8.

${ }^{6}$ Aljovín de Losada, Cristóbal, Prácticas políticas y formación de ciudadanía, en Chile-Perú, Perú-Chile: 1820-1920. Desarrollos políticos, económicos y culturales (Valparaíso, Ediciones Universitarias de Valparaíso, 2005), p. 116.

${ }^{7}$ Chiaramonti, Gabriella, A propósito del debate Herrera-Gálvez de 1849: breves reflexiones sobre el sufragio de los indios analfabetos, en ALJOvín DE LOSADA, Cristóbal - LÓPEZ, Sinesio (editores), Historia de las elecciones en el Perú (Lima, Instituto de Estudios Peruanos, 2005).

${ }^{8}$ NúNẼE, Francisco La participación electoral indígena bajo la Constitución de Cádiz (18121814), en Aljovín de Losada, Cristóbal - López, Sinesio (editores), Historia de las elecciones en el Perú (Lima, Instituto de Estudios Peruanos, 2005).

${ }^{9}$ Ibíd., p. 361.

${ }^{10}$ Chiaramonti, Gabriella, A propósito del debate Herrera-Gálvez de 1849: breves reflexiones sobre el sufragio de los indios analfabetos, en ALJOvín DE LOSADA, Cristóbal - LÓPEZ, Sinesio (editores), Historia de las elecciones en el Perú (Lima, Instituto de Estudios Peruanos, 2005).

${ }^{11}$ BNP: "Expediente sobre petición presentada por Bernardino Alarcón, vecino español de Puquina, para que no se dé participación excesiva a los sujetos de raza incaica en la integración de los ayuntamientos, Puquina”, mayo de 1813, citado por Chiaramonti, Gabriella, A propósito del debate Herrera-Gálvez de 1849: breves reflexiones sobre el sufragio de los indios analfabetos, en Aljovín de Losada, Cristóbal - López, Sinesio (editores), Historia de las elecciones en el Perú (Lima, Instituto de Estudios Peruanos, 2005), p. 342. 
leer y escribir tendrían derecho a sufragar. No obstante, en 1828 la condición de "analfabetos" les cedió la posibilidad de participación de la ciudadanía activa. La convención de 1856-1857 estableció el sufragio directo; sin embargo, la posterior Constitución de 1860 reinstauró el "alfabeto" como requisito para sufragar; subsiguientemente la ley de 1861 retornará al sistema elitista. Aljovín de Losada ${ }^{12}$ precisa que los indígenas votaban en bloque o corporativamente por los candidatos que ellos determinaban, asumiendo posturas comunitarias tanto en las elecciones, así como en la resolución de conflictos locales o regionales.

Sólo a partir de las modificaciones de la ley electoral peruana de 1867 se abrió el derecho a voto a todos los varones de 21 años, que tuvieran bien raíz y que cancelaran algún tipo de contribución a la Hacienda pública, permitiendo a los indígenas ejercer su derecho ciudadano mediante el voto popular, generando, quizás, el surgimiento o consolidación de elites con poder local. Pese a lo anterior, esta regulación electoral no estuvo exenta de fuertes críticas de grupos conservadores en el Parlamento peruano.

La intermitente participación electoral durante el siglo XIX significó, hipotéticamente, que las demandas políticas se concentraran en otro tipo de estrategias discursivas y políticas, como fueron los petitorios por el acceso a educación o la inscripción de títulos de dominio ${ }^{13}$. La demanda educacional refleja un compromiso político y ciudadano de los indígenas andinos que opera desde la segunda mitad del siglo XIX, y que aun con la presencia del Estado chileno, seguirán emitiendo quejas por la ausencia y falta de compromiso en materia educativas de los agentes estatales ${ }^{14}$. Recapitulando, la difusión de las ideas de la ciudadanía liberal durante el siglo XIX fue asumida rápidamente por los segmentos indígenas, como una posibilidad para reforzar los márgenes de autonomía en la gestión de sus recursos ${ }^{15}$.

\section{LOS INDÍGENAS ANDINOS Y EL ESTADO-NACIÓN PERUANO}

San Martín, a inicios de la república peruana, intentó contrarrestar el principio de la desgracia política de los grupos de indios, para lo cual abolió la denomina-

\footnotetext{
${ }^{12}$ Aljovín de Losada, Cristóbal, Sufragio y participación politica. Perú: 1808-1896, en Aljovín de Losada, Cristóbal - López, Sinesio (editores), Historia de las elecciones en el Perú (Lima, Instituto de Estudios Peruanos, 2005), p. 40.

${ }^{13}$ RuZ, Rodrigo, Escrituras, olvido y memoria. Títulos de propiedad, olvido y prácticas en la tierra aymara. Tarapacá, Siglo XIX/XX, en Revista Dialogo Andino, 26 (2005).

${ }^{14}$ ANDaur, Carolina, Descubrimiento y conquista del ejercicio ciudadano. Las poblaciones andinas de Tarapacá a mediados del siglo XIX, en Los Andes entre el tributo y la Nación: las comunidades aymaras durante el siglo XIX (Iquique, Universidad Bolivariana, 2005).

${ }^{15}$ Chiaramonti, Gabriella, A propósito del debate Herrera-Gálvez de 1849: breves reflexiones sobre el sufragio de los indios analfabetos, en Aljovín DE LOSADA, Cristóbal - López, Sinesio (editores), Historia de las elecciones en el Perú (Lima, Instituto de Estudios Peruanos, 2005); Díaz Araya, Alberto, Chilenización y comunidad andina. Educación, reclutamiento militar y articulaciones en Putre. 1883-1929 (Tesis de Magíster en Antropología Social, Instituto de Investigaciones Arqueológicas y Museo R. P. Gustavo Le Paige, Universidad Católica del Norte, San Pedro de Atacama, 2006).
} 
ción de "indios o naturales" junto con el "tributo", ya que eran signos del viejo "señorío" y del "despotismo" hispano; remanentes de la antigua institucionalidad colonial conocida en la literatura como la "república de indios" y la "república de españoles"16. De acuerdo con Thurner ${ }^{17}$, con la liberación de la dominación española y la posterior extinción del tributo, también desaparecen los "indios", siendo ahora reconocidos en todo orden legal como "peruanos". Aquellas disposiciones tributarias ciertamente generaron inestabilidad económica en la naciente república peruana.

Por su parte, dentro del afán liberador y fiel a la comunidad universal, Simón Bolívar acuña la expresión afrancesada de indígenas para designar a los ex indios y reemplazar la denominación anterior de "peruanos”. Bolívar, en unos decretos de 1824 y 1825 , confirma la abolición del tributo indígena, suprime a su vez la propiedad corporativa sobre las tierras de los indígenas y los títulos de nobiliarios (p. ej., caciques), agregando que se eliminan las faenas, séptimas, mitas o pongos, en definitiva todos los servicios personales gratuitos. La abolición de la propiedad comunitaria, fue rápidamente modificada ya que se temió que sirviera sólo para convalidar futuros despojos de tierras indígenas. Estas disposiciones señalaron que sólo los indígenas alfabetizados podrían ejercer derecho sobre sus tierras.

Debido a la falta de organización de la fragmentación de los territorios comunales y al desinterés de los propios comuneros, éstas medidas carecieron de efectos prácticos. Los historiadores Contreras y Cueto ${ }^{18}$ señalan que el escenario legal de las propiedades de tierras indígenas permaneció en un verdadero "limbo", debido a que en aquellos conflictos que no fueran contrarios a la legislación republicana, regirían las antiguas leyes de Indias. Como a los republicanos poco les interesaba la situación de los indígenas y éstos no generaron reclamos ni cambios, quedaron definitivamente ligadas al orden jurídico colonial como un estatuto de "costumbres ancestrales"19. Las medidas bolivarianas buscaban integrar al Estado peruano al numeroso componente indígena andino, aunque en la práctica se conservaron (entrado el siglo XIX) las viejas estructuras tributarias coloniales, a las que estaban acostumbrados la población indígena y los terratenientes hispanos. Más aún, la economía de la República del Perú, que recién daba sus primeros pasos, no podía mantenerse por si sola con la tributación "ciudadana”, generando una

${ }^{16}$ Contreras, Carlos, Estado republicano y tributo indigena en la sierra central en la postIndependencia, en Revista Histórica, 13 (Lima, Pontificia Universidad Católica del Perú, 1989); Walker, Charles, De Tupác Amaru a Gamarra: Cusco y la formación del Perú Republicano 17801840 (Cusco, Centro de Estudios Regionales Andinos Bartolomé de Las Casas, 1999).

${ }^{17}$ Thurner, Mark, Los indios y la repúblicas entre 1830-1880, en Historia de América Andina, Creación de las repúblicas y formación de la nación (Quito, Universidad Andina Simón Bolívar, 2003), V.

${ }^{18}$ Contreras, Carlos - Marcos Cueto, Historia del Perú contemporáneo (Lima, Instituto de Estudios Peruanos, 2000).

${ }^{19}$ Ibíd., p. 69. Thurner, Mark, Republicanos y la comunidad de peruanos: Comunidades políticas inimaginadas en el Perú postcolonial, en Revista Histórica, 20 (Lima, Pontificia Universidad Católica del Perú, 1996) 1, entrega interesantes ejemplos donde distintos comuneros de los Andes centrales apelan a la vigencia de las Leyes de Indias para acceder legítimamente a los pastos cordilleranos. 
crisis fiscal por las necesidades del gasto público y por endeudamiento, lo que a la postre significó que en 1826 Hipólito Unanue mediante la Carta Política restableciera la "contribución correspondiente a los indígenas" ${ }^{20}$. Recae nuevamente sobre los indígenas una parte del financiamiento del Estado, sin participación en las diversas actividades que demandaba la estructuración de la naciente república peruana. Se estableció de este modo una suerte híbrida "ciudadanía tributaria" republicana ${ }^{21}$, finalizando sólo a mediados del siglo XIX con la abolición de la contribución indígena.

Para la década del ' 30 se exigió eliminar los trabajos forzados y la servidumbre de los indígenas, dictámenes que los gobiernos de corte liberal implementaron lentamente hacia este segmento de la población peruana. Pese a lo anterior, existió en algunos sectores conservadores el interés porque los indígenas no se enajenaran de sus tierras, para que siguieran cumpliendo con las labores de la mita o el servicio personal. El aporte de los indígenas a las arcas del fisco peruano mediante la contribución era cercano al $40 \%$ y aumentaba en los sectores departamentales. González ${ }^{22}$, sobre la base del padrón de contribuyentes del año 1845 , sostiene que para la provincia de Tarapacá la contribución indígena representó 82,5\% del total de ingresos fiscales ${ }^{23}$. La contribución indígena también significó un universo de relaciones y discursos contradictorios entre el Estado y los indígenas, debido a que operaban articulaciones en base a viejas matrices coloniales. Walker ${ }^{24}$ argumenta que este escenario significó abrir instancias de negociación entre el Estado y los actores indígenas.

Evaluando en perspectiva lo expuesto, la situación de las comunidades andinas durante la primera mitad del siglo XIX es ambigua, debido a que se desplaza contradictoriamente entre un status de sujeto tributario remanente de los vestigios coloniales y el de un ciudadano propietario, libre y con derechos múltiples. Esta ambigüedad discursiva (moderna y ciudadana) y práctica (praxis colonial) tanto en contenidos sociales como políticos caracterizó a su vez las tensas relaciones entre la masa indígena y el Estado-ciudadano durante la primera mitad del siglo XIX, generando una especie híbrida de "ciudadanía tributaria".

${ }^{20}$ La Constitución de 1826, conocida como la Vitalicia era mucho más rígida que los reglamentos decretados por San Martín o Bolivar. Esta excluía de la condición ciudadana no sólo a los que realizaban trabajos domésticos o servidores manuales, sino que directamente a la población analfabeta, como corresponde al caso de los indígenas, ya que actualizó los anteriores requisitos sobre lecto-escritura que en 1823 habían sido postergados en su aplicación para el ejercicio de los derechos ciudadanos. En la Constitución de 1826 era incompatible con la regulación de las libertades e igualdades jurídicas en el Perú. Un estudio jurídico mucho más detallado en Urquieta, Débora, De campesino a ciudadano. Aproximación jurídica (Cusco, Centro Bartolomé de Las Casas, 1993).

${ }^{21}$ Thurner, cit. (n. 1), p. 197.

${ }^{22}$ GONZÁLEZ, Héctor, Los aymaras de la región de Tarapacá y el período republicano temprano (1821-1879) (Documento de Trabajo de la Comisión de Verdad Histórica y nuevo trato, Sub grupo Pueblo Aymara, Santiago, 2002).

${ }^{23}$ Ibíd.

${ }^{24}$ Walker, Charles, De Tupác Amaru a Gamarra: Cusco y la formación del Perú Republicano 1780-1840 (Cusco, Centro de Estudios Regionales Andinos Bartolomé de Las Casas, 1999). 
La mantención de estructuras virreinales en un formato político liberal responde a la hibridez social, donde los indígenas apelando a su condición de ciudadanía podían demandar educación y protección legal de parte del Estado, y a su vez, bajo la condición de tributarios podían apelar a un reconocimiento estatal de sus títulos coloniales sobre repartimientos, lo que significaría la continuidad del "Pacto colonial" entre los indios y el Estado bajo un nuevo formato ${ }^{25}$. Aquel "Pacto Colonial" pervivió hasta el 5 de julio de 1854, cuando el tarapaqueño Ramón Castilla abolió el tributo indígena, debido a que el peso de la contribución indígena dentro de las rentas del Estado estaba en detrimento, gracias a un ciclo de bonanza económica producto de las exportaciones de "guano" que quintuplicaron las arcas fiscales peruanas.

\section{JUSTICIA EN LAS COMARCAS ANDINAS}

A comienzos del siglo XIX, las medidas políticas del Estado borbónico generaron la desaparición de los caciques hereditarios en Tarapacá, los cuales hasta entonces habían actuado como interlocutores entre la administración hispana y las comunidades andinas a nivel local, dentro de un cuadro de control político ${ }^{26}$. Como relevo, la figura del alcalde de indios (o "varayocs") cobró mayor significación comunitaria al ser un cargo de elección anual, posibilitando la democratización del poder local, debido a que cualquier hombre casado de la comunidad podía ser cacique ${ }^{27}$. Bajo el principio andino de la dualidad, en algunas comunidades se nombrarán dos caciques según las parcialidades (“arajj sayas” - "manka sayas”) que dividen en dos mitades a las comunidades ${ }^{28}$. González sostiene que dentro

${ }^{25}$ Ibíd., pp. 11-12, como también lo han expuesto Thurner y Contreras, González enfatiza que la contribución de indios perfilaba una clasificación estatal semejante a la colonial; sin embargo para 1826 se anunció la creación de la contribución de castas, incluyendo a los no indios, fundiendo elementos fiscales, raciales y sociales, principalmente entre los segmentos poblacionales mestizos y pobres. A su vez, este autor señala que la contribución indígena no era la misma que la colonial, debido a que los indios no eran meros tributarios de sus vencedores, ahora eran rotulados como ciudadanos con la responsabilidad de contribuir al naciente Estado. Este sistema individualiza la responsabilidad de los contribuyentes, volviendo capitación lo que antiguamente fue concebido como la imposición colectiva a un ayllu, comunidad o parcialidad, lo que fue significó una ventaja para la comunidad andina, ya que al no existir un monto global fijo, la comunidad ya no estaba obligada a asumir las cargas de ausentes o muertos, desapareciendo la tipología de originarios y forasteros, disfrutando todos de igualdad de derechos.

${ }^{26}$ Dunaway, Nicole, Crisis del cacicazgo, participación politica indígena y estado colonial en los corregimientos de Arica y Tarapacá, 1780-1815 (Tesis para optar al Grado de Magíster en Historia, Mención en Etnohistoria, Facultad de Filosofía y Humanidades, Escuela de Postgrado, Universidad de Chile, 2003). Castro, Luis - Figueroa, Carolina, Continuidad y cambio: la institución del cacicazgo en Tarapacá (norte de Chile) desde el lapso tardo-colonia al periodo republicano (ms. 2005).

${ }^{27}$ O’Phelan, Scarlet, Kurakas sin sucesiones. Del cacique al alcalde de indios. Perú y Bolivia 1750-1835 (Cuzco, CBC, 1997).

${ }^{28}$ GONZÁLEZ, cit. (n. 11). Una discusión mayor sobre las parcialidades entre las comunidades aymaras en el norte de Chile en MARTínez, Gabriel , El sistema de los Uywiris en Isluga, en Espacio y Pensamiento (La Paz, Hisbol, 1989); VAn Kessel, Juan, Cuando arde el tiempo sagrado (La Paz, Hisbol, 1992); Díaz Araya, Alberto, Fiesta y fútbol entre los Aymaras del norte de Chile: 
de este contexto adquirió mayor importancia a nivel sociopolítico el pueblo o la comunidad, la cual se congrega mediante los cabildos pueblerinos ("kawiltu"), principalmente con ocasión de las grandes fiestas patronales, carnavales u otros eventos $^{29}$. Con la Constitución de Cádiz de 1812, la justicia será asumida por el Alcalde, cargo que solamente después de la independencia (1821), será confirmado en sus responsabilidades legales a nivel comunitario.

La Constitución peruana de 1823 en su artículo 142, expresaba que los alcaldes de las comunidades serán al mismo tiempo los jueces de paz de su respectiva población, conociendo las demandas verbales, civiles de menor cuantía y criminales sobre injurias leves y delitos menores que merecieran una moderada corrección en las Prefecturas y Subprefecturas ${ }^{30}$. Se debía administrar en cada localidad la

el caso de Sotoca y Chiapa, en Boletín International Fellowship Program - Leadership for Social Justice Institute, 13 (2006).

${ }^{29}$ En otras comunidades andinas del norte chileno donde hemos desarrollado estudios de localidades, como son Sotoca, Sibaya, Laonzana y Chiapa hemos podido constatar tanto en la documentación como en las prácticas rituales la significación y poder que detentaba el cacique, los "mallkus" o los "jilakatas" hasta entrado el siglo XX como autoridades comunitarias. Hoy durante la fiesta patronal el alférez, que también es un cargo comunitario y religioso, asume por los días de la festividad el poder local que le confiere la comunidad; una inferencia podría ser que el alférez constituye la representación que en antaño tuvo el alcalde de indios. Para la temporada estival el carnaval (anata) es otro evento que congrega a la comunidad, y la gente retorna desde las ciudades a celebrar este y otros rituales, demarcándose las parcialidades a través de los "Arajj Saya" ("los de arriba") y los "Manka Saya" ("los de abajo") formando grupos o pandillas con sus respectivos alférez y comparsas de músicos. Para la limpieza de los canales algunas autoridades encargadas de los turnos o mitas del agua asumen ciertas responsabilidades comunitarias.

${ }^{30}$ BNP: "Constitución de la República del Perú, 1823". Una revisión sintomática sobre la administración pública es desarrollada por Del Castillo y León, quienes enfatizan que los prefectos debían, con el Estatuto Provisional de 1821, encargarse del gobierno económico, la hacienda pública y la administración de justicia, principalmente. Con los años sus atribuciones fueron mayores: iban desde la represión de los adversarios políticos del gobierno de turno, la conservación del orden público y el sofocamiento de revueltas, hasta el cuidado y conservación de los monumentos públicos y la mantención de los caminos. Les competía además el aspecto educativo, pues debían velar por la enseñanza en las escuelas y promover, sobre todo, la educación primaria. Desempeñaban la inspección del ramo de correos y la protección de la libertad de prensa. Una de las obligaciones desde 1830, y que reviste gran importancia, era la que disponía la presentación al gobierno central del número de nacidos, casados y fallecidos en sus respectivos departamentos, es decir, una estadística de la población. Otro aspecto fue la obligación de realizar, durante el primer año de su mandato, una visita a todo el departamento con el fin de recoger las inquietudes de la población y controlar a las diversas autoridades que de él dependían. Posteriormente, habrían de redactar una memoria acerca del viaje, dirigida a su respectiva junta departamental y al gobierno central en Lima. Aunque se encuentran reglamentadas sus funciones en fechas tan tempranas como 1830, se lamentaba un ministro de gobierno que en la constitución fuesen estas normas tan generales que causaban serios problemas, principalmente económicos, y pedía que se resolviera con prontitud dicha situación. Los subprefectos, en cambio, estuvieron abocados al cobro de las contribuciones fiscales, así como de velar por la tranquilidad y el buen orden dentro de su provincia. Los prefectos y subprefectos debían ser elegidos entre los ciudadanos notables de cada departamento. Esto no se cumplió necesariamente. Algunos prefectos, por ejemplo, hacen notar en sus memorias la ausencia de ciudadanos debidamente instruidos y con la preparación necesaria para desempeñar cargos públicos. Querrían explicar así, tal vez, la presencia constante de miembros de las 
"justicia en nombre de la nación", con esto se descartaba cualquier posibilidad de particularismo jurisdiccional, por lo tanto, las prácticas consuetudinarias de resolución de conflictos al interior de las comunidades debían dar paso en definitiva al sistema judicial republicano ${ }^{31}$.

Los gobiernos locales influenciaron directamente en la administración de la justicia a nivel comunitario. Los alcaldes (que en un primer periodo asumieron labores como jueces de paz) eran elegidos entre los ciudadanos de las parroquias y provincias, generando incluso clientelismo político y económico al interior de la estructura comunal. Para 1826 el aparato jurisdiccional fue especializándose. Las cortes de distrito judicial conocían en segunda y en tercera instancia todas las causas civiles del fuero común -entre ellas los litigios sobre tierras de indios, hacienda pública, comercio, entre otros-, dirimían competencias entre juzgados y quejas contra los tribunales y autoridades eclesiásticas. Los partidos judiciales se establecieron en cada provincia con jueces de letras para resolver asuntos contenciosos y eran responsables ante la corte judicial distrital. Formalmente se instituyeron los jueces de paz en cada pueblo "con más de 100 almas", un juez de paz y un alcalde para las conciliaciones si la población era superior a 200 personas. Los cargos de alcalde y juez de paz eran por dos años, pudiendo ser reelegidos, eran concejiles y ningún ciudadano podía rehusarse a asumirlo. Además, en esta carta jurídica se abolieron las penas crueles y la restricción de la pena capital ${ }^{32}$.

En 1828, se declaró la independencia del Poder Judicial en el Perú. Los juzgados de primera instancia redefinieron sus competencias incluyendo las sucesiones de patronatos y capellanías eclesiásticas. La administración de la justicia ratificó "a nombre de la nación" y se institucionalizó la triple instancia desde los juzgados de paz para las conciliaciones ${ }^{33}$. A partir de la Constitución de 1839 dictada por Agustín Gamarra el gobierno peruano asume el control político del Poder Judicial, injiriendo en las designaciones de los cargos subalternos de la administración a nivel de Prefecturas, Subprefecturas y de gobernadores y tenientes alcaldes ${ }^{34}$. Este

fuerzas armadas en tales puestos. El prefecto daba cuenta de las actividades cumplidas por la gendarmería o fuerza policiales a su mando (en comisarías, cárceles públicas y reformatorios), la instrucción pública, el servicio judicial y municipal, el movimiento portuario, ferrocarrilero y de pasajeros en tambos y hoteles, el comercio y la industria, correos y telégrafos, sociedades de beneficencia, la construcción o arreglos de caminos, puentes y otras obras públicas, etc. Además iban acompañadas, muchas de ellas, por anexos estadísticos que incluían, en algunos casos, planos y mapas. Véanse: Del Castillo, Miguel - León, Angélica, Las Prefecturas en el Perú (1823-1919). Catálogo de Memorias de gobierno de Prefectos y Subprefectos, en Revista del Archivo General de la Nación, 16 (2a época, Lima, 1997), pp. 210-212.

${ }^{31}$ Ardito, Wilfredo, Justicia de paz en el Perú, en Allpanchis. Instituto de Pastoral Andina, año 34, $\mathrm{N}^{\circ} 60$ (Cuzco, 2002).

${ }^{32}$ BNP: "Constitución de la República del Perú, 1826”.

${ }^{33}$ BNP: “Constitución de la República del Perú, 1828”.

${ }^{34}$ Según lo expuesto, los documentos expresan lo siguiente: "Iquique Marzo 27 de 1878. Señor Coronel Prefecto de esta Provincia Litoral. En contestación al estimable oficio de US. De 18 del corriente, en que se sirve adjuntarme el acta de la elección de los ciudadanos que deben formar el concejo del distrito de Tarapacá, me es satisfactorio decir a US que dicha elección ha sido calificada por este concejo y que no teniendo impedimento legal el Alcalde Don José Camilo Romero, el Teniente Alcalde Don Eugenio Castilla y los regidores Don Juan Vernal y Castro, Juan Vernal Garcia y Don 
escenario fue generando un ambiente de intranquilidad en torno al centralismo del ejecutivo, caracterizado por críticas a nivel parlamentario y movilizaciones en algunas ciudades peruanas, que exigían la democratización del Estado, incluso en las comunidades donde gobernadores y jueces de paz eran designados por un año ${ }^{35}$, tras presentarse una terna de ciudadanos ejemplares al gobierno central ${ }^{36}$.

\section{Jueces de paZ y COMUnidad. Descripción de Casos}

Los jueces de primera instancia y los jueces de paz establecieron una compleja interacción con la comunidad, ya sea para dirimir conflictos internos, así como resolver situaciones cotidianas, sobre todo aquellos jueces que pertenecían a la comunidad. El juez de primera instancia, debía ser ciudadano y de profesión abogado, era quien se encargaba de los diferendos civiles de mayor cuantía ${ }^{37}$. En materia de diferendos por la propiedad de la tierra, el criterio de mayor o menor cuantía, era el valor de la propiedad en cuestión, determinada por la tasación elaborada por los peritos.

De acuerdo con Aguilar y Cisternas ${ }^{38}$, entre las funciones del juez de primera instancia era el aceptar los procesos judiciales, trasladar provisiones o recursos a las partes interesadas a través del escribano público, dictar los autos, nombrar a peritos y al promotor fiscal; realizar la información sumaria de los testigos implicados en los casos, aceptar apoderados, despachar recursos y decretos para los jueces de paz. En caso de juicio por tierra y agua debían validar las tasaciones (junto al promotor fiscal), aprobar los deslindes, y decretar la restitución por despojo de tierra. En general, el juez de primera instancia recibía y remitía los despachos y peticiones de los recursos ${ }^{39}$.

Casimiro Trillo y los suplentes José Ramírez, Don Manuel Soto Flores y Don Joaquín del Carpio, se ha de servir US que el Gobernador del distrito citado, instale el Concejo de Tarapacá tomando el juramento de ley, tanto a los propietarios como a los suplentes en conformidad con la suprema resolución de febrero de 1877”. APT, volumen 23, sin foja, 1878.

${ }^{35}$ BNP: “Constitución de la República del Perú, 1839". Según el artículo 137 de esta Constitución, para ser Gobernador de distrito se requería ser peruano de nacimiento, ciudadano en ejercicio (saber leer y escribir) y ser nacido en el distrito o avecindado en él por cinco años al menos. La duración en el cargo era de dos años, pudiendo ser removidos antes a juicio del Ejecutivo.

${ }^{36}$ Una información documental que encontramos en Lima ilustra la nominación de lugareños en cargos de jueces de paz, al respecto se detallan los nombramientos para el caso de la zona de Tarapacá (medidas que para el área de estudio son homologables) de José Ramírez (Tarapacá), Marianao Chávez (Guatacondo), Eugenio Guante (Laonzana), Manuel García (Guaviña), Manuel Pereira (Coscaya), Juan Berreda (Camiña), Ignacio Tauca (Miñi Miñi), Antonio Nuñez (Sibaya), Andrés Ramírez (Limacsiña), Mariano Argote (Usmagama), Mariano Tayna (Sipiza), Rumaldo Esteban (Guasquiña), Tomás Yugra (Chiapa), Calixto Velarde (Mocha), Mateo Caquisane (Sotoca), Feliciano Mamani (Cariquima), Mariano Mamani (Isluga). AGN, Ministerio de Justicia, Prefectura de Tarapacá, legajo 129, 1872.

${ }^{37}$ BNP: "Constitución de la República del Perú, 1828".

${ }^{38}$ Aguilar, Julio - Cisternas, Priscilla, Tierra y Agua en el Perú Sur Andino: Conflictos y Estrategias de Resolución en las Comunidades Indígenas 1830-1880 (Tesis para optar al grado de Profesor de Historia y Geografía, UTA, 2007).

${ }^{39}$ Ibíd. 
Los tribunales de la Subprefectura de Tarapacá, sancionaron con la reclusión de los pobladores que alteraban el orden público, mediante actos contrarios a la jurisprudencia peruana. Si en cada localidad con más de 100 personas había un juez de paz sujetos a jueces de primera instancia, es dable destacar que en pueblos del sur peruano existían cárceles para recluir a todo aquel que alterara la normativa republicana. La institución de la cárcel en los poblados andinos -construida de adobes y piedras con un solo cuarto- fue un artefacto que se erigió como estructura de disciplina bajo los preceptos legales. La cuadrícula de la vigilancia estatal se materializaba en todos los rincones de la nación, lo que podría entenderse bajo los fundamentos de Foucault, como la implantación de una maquinaria cuyo fin último era generar bajo el Estado de derecho una "sociedad disciplinada" en los Andes ${ }^{40}$. A continuación se presenta un registro de las cárceles en la Subprefectura de Tarapacá:

\section{Cuadro No 1}

Estado de las cárceles de la provincia de Tarapacá, 1873

\begin{tabular}{|l|c|c|c|c|c|c|c|}
\hline $\begin{array}{c}\text { Lugar } \\
\text { de la cárcel }\end{array}$ & Superficie & Patios & $\begin{array}{c}\text { Salas de } \\
\text { hombres }\end{array}$ & $\begin{array}{c}\text { Salas de } \\
\text { mujeres }\end{array}$ & $\begin{array}{c}\text { Cabida } \\
\text { de presos }\end{array}$ & $\begin{array}{c}\text { Habitacio- } \\
\text { nes para } \\
\text { empleados } \\
\text { guardias }\end{array}$ & $\begin{array}{c}\text { Material de } \\
\text { construcción }\end{array}$ \\
\hline Tarapacá & $10 \times 6$ & - & 1 & - & 10 & - & Adobe y piedra \\
\hline Laonzana & $12 \times 5$ & - & 1 & - & 8 & - & Adobe y piedra \\
\hline Guaviña & $14 \times 6$ & - & 1 & - & 8 & - & Adobe y piedra \\
\hline Coscaya & $10 \times 4$ & - & 1 & - & 6 & - & Adobe y piedra \\
\hline Pica & $20 \times 10$ & 1 & 1 & 1 & 16 & 1 & Adobe y piedra \\
\hline Matilla & destruida & - & - & - & - & - & - \\
\hline Tirana & destruida & - & - & - & - & - & - \\
\hline Mamiña & $20 \times 12$ & 1 & 1 & 1 & 16 & - & Adobe y piedra \\
\hline Parca & $8 \times 5$ & - & 1 & - & 6 & - & Adobe y piedra \\
\hline Macaya & $8 \times 5$ & - & 1 & - & 6 & - & Adobe y piedra \\
\hline Sibaya & destruida & - & - & - & - & - & - \\
\hline Limacsińa & destruida & - & - & - & - & - & - \\
\hline Mocha & $8 \times 5$ & - & 1 & - & 6 & - & Adobe y piedra \\
\hline Usmagama & $8 \times 5$ & - & 1 & - & 6 & - & Adobe y piedra \\
\hline Sipisa & $10 \times 6$ & - & 1 & - & 6 & - & Adobe y piedra \\
\hline Guasquiña & $6 \times 4$ & - & 1 & - & 5 & - & Adobe y piedra \\
\hline Chiapa & $15 \times 10$ & 1 & 1 & 1 & 12 & 1 & Adobe y piedra \\
\hline Sotoca & $8 \times 5$ & - & 1 & - & 6 & - & Adobe y piedra \\
\hline Isluga & destruida & - & - & - & - & - & - \\
\hline Cariquima & destruida & - & - & - & - & - & - \\
\hline Camiña & destruida & - & - & - & - & - & - \\
\hline
\end{tabular}

Fuente: AGN: Ministerio de Justicia, Corte de Justicia Superior, Moquegua 1857-1875. Oficio s/n "Estado que manifiesta el material de las Cárceles de toda la Provincia de Tarapacá en el año 1873”.

\footnotetext{
${ }^{40}$ Foucault, Michel, Vigilar y castigar (México, Siglo XXI Editores, 1997).
} 


\section{Cuadro No 2}

Detalles del movimiento presos de la cárcel de la provincia de Tarapacá, 1873

\begin{tabular}{|c|c|c|c|c|c|c|c|c|c|c|c|}
\hline Delitos & $\mathrm{N}^{\circ}$ & $\mathrm{H}$ & $\mathrm{M}$ & $\mathrm{Edad}$ & $\mathrm{N}^{\circ}$ & Indig. & Catól. & Peruan. & Boliv. & I.P. & S. I. \\
\hline $\begin{array}{c}\text { Homici- } \\
\text { dios }\end{array}$ & 4 & 14 & 3 & menores de 9 & 0 & & & & & & \\
\hline $\begin{array}{c}\text { Hurto } \\
\text { Robos }\end{array}$ & 1 & 6 & & de 9 a 15 & 0 & & & & & & \\
\hline $\begin{array}{c}\text { Flagela- } \\
\text { ción }\end{array}$ & 1 & & & de 18 a 25 & 3 & & & & & & \\
\hline $\begin{array}{c}\text { Abuso } \\
\text { de auto- } \\
\text { ridad }\end{array}$ & 1 & & & de 25 a 30 & 2 & & & & & & \\
\hline Lesiones & 1 & & & de 30 a 40 & 4 & & & & & & \\
\hline $\begin{array}{c}\text { Falsifica- } \\
\text { ción }\end{array}$ & 1 & & & de 40 a 50 & 5 & & & & & & \\
\hline $\begin{array}{c}\text { Secues- } \\
\text { tro }\end{array}$ & 1 & & & de 50 a 60 & 1 & & & & & & \\
\hline Injurias & 1 & & & de 60 a 70 & 0 & & & & & & \\
\hline & & & & de 70 a 80 & 0 & & & & & & \\
\hline más de 80 & 0 & & & & & & \\
\hline se ignora & 1 & & & & & & \\
\hline
\end{tabular}

Siglas y abreviaturas: $\mathrm{H}=$ hombres; $\mathrm{M}=$ mujeres; Indig. = indígenas; I.P. = instrucción primaria; S.I. $=\sin$ instrucción.

\section{Sigue a continuación}

\begin{tabular}{|c|c|c|c|c|c|c|c|c|}
\hline Oficio & $\mathrm{N}^{\circ}$ & $\begin{array}{l}\text { Salud } \\
\text { mental }\end{array}$ & $\mathrm{N}^{\circ}$ & $\begin{array}{c}\text { Salud } \\
\text { corporal }\end{array}$ & $\mathrm{N}^{\circ}$ & Procesados & $\mathrm{N}^{\circ}$ & Condenados \\
\hline Cocinero & 1 & Locos & 0 & Enfermos & 0 & $\begin{array}{l}\text { Manuel L. Núñez, por } \\
\text { injurias en el sumario }\end{array}$ & 1 & 0 \\
\hline $\begin{array}{l}\text { Costu- } \\
\text { rero }\end{array}$ & 1 & $\begin{array}{l}\text { Demen- } \\
\text { tes }\end{array}$ & 0 & Sanos & 17 & $\begin{array}{l}\text { Narciso Hidalgo, por } \\
\text { injurias en el sumario } \\
\text { tribunal }\end{array}$ & 1 & 0 \\
\hline $\begin{array}{l}\text { Agricul- } \\
\text { tores }\end{array}$ & 5 & $\begin{array}{l}\text { De sano } \\
\text { juicio }\end{array}$ & 17 & & & $\begin{array}{l}\text { Manuel Núñez P., por } \\
\text { falsific. de diligencia } \\
\text { judicial }\end{array}$ & 1 & 0 \\
\hline Arrieros & 3 & & & & & $\begin{array}{l}\text { Félix Aranibar, por } \\
\text { abuso de autoridad }\end{array}$ & 1 & 0 \\
\hline $\begin{array}{c}\text { Artesa- } \\
\text { nos }\end{array}$ & 4 & & & & & $\begin{array}{c}\text { Asencio Cómara, por } \\
\text { secuestro }\end{array}$ & 1 & 0 \\
\hline $\begin{array}{l}\text { Comer- } \\
\text { ciantes }\end{array}$ & 2 & & & & & $\begin{array}{c}\text { José A. Pérez, por } \\
\text { hurto }\end{array}$ & 1 & 0 \\
\hline
\end{tabular}




\begin{tabular}{|c|c|c|c|c|c|c|}
\hline $\begin{array}{l}\text { Sin } \\
\text { oficio }\end{array}$ & 1 & & & $\begin{array}{c}\text { Irma Cornejo, Tomás } \\
\text { Díaz y Justina Lorca, } \\
\text { por robo }\end{array}$ & 3 & 0 \\
\hline & & & & $\begin{array}{c}\text { Pedro Marca y } \\
\text { Eustaquia Linares, por } \\
\text { homicidio }\end{array}$ & 2 & 0 \\
\hline & & & & $\begin{array}{c}\text { Francisco Oviedo, por } \\
\text { flagelación }\end{array}$ & 1 & 0 \\
\hline & & & & $\begin{array}{c}\text { Gaspar Caucoto, } \\
\text { Gavina Valverde y } \\
\text { Martín Morales, por } \\
\text { robo }\end{array}$ & 3 & 0 \\
\hline & & & & $\begin{array}{l}\text { Manuel Montaño y } \\
\text { Mariano Terán, por } \\
\text { homicidio }\end{array}$ & 2 & 0 \\
\hline Total & 17 & 17 & 17 & & 17 & 0 \\
\hline
\end{tabular}

Fuente: AGN: Ministerio de Justicia, Corte de Justicia Superior, Moquegua 1857-1875, oficio s/n: "Estado que manifiesta el personal y movimiento de la cárcel de Tarapacá, bajo condiciones ó puntos de vista que se expresan, durante el año $1873^{\prime 41}$

El juez de paz era en la gran mayoría de los casos un representante de la comunidad. No era un funcionario permanente, sino que su cargo era rotativo entre los comuneros (1 un año en el ejercicio). Durante gran parte del siglo XIX el juez de paz estructuró diversos tipos de relaciones de poder con las autoridades municipales y políticas distritales, debido a su origen municipal y a su naturaleza vecinal. Asimismo, los jueces fueron considerados como una "autoridad" reconocida por la comunidad dada su condición de "buen vecino", mediador de conflictos intracomunitarios ${ }^{42}$. No obstante, al ser un cargo rotativo, no siempre la comunidad sabía exactamente quién ostentaba el cargo de juez de paz. Lo anterior se advierte en un juicio sobre el despojo de tierras en Chapiquiña el 9 de enero de 1878 de acuerdo a los descrito por Aguilar y Cisternas (2007). Puntualmente, Gregorio Larba -indígena de la localidad de Belén- envía un recurso al juez de primera instancia de Arica apelando que lo han confundido con el juez de paz de Belén en un diferendo promovido con meses de duración: "Señor Jues de $1^{a}$ Instancial Gregorio Larva indígena vecino de Belen y de trancito en esta ciudad ante $U$. respetuosamente me presento y digo: - que Gregorio Apas ha seguido juicio de despojo judicial en mi contra, suponiendome jues de paz del lugar de mi residencia, siendo asi que Don Eugenio Pilco es el Juez de Belén" 43.

Este tipo de acusaciones que señala Gregorio Larva es frecuente en la documentación, debido a que los jueces de paz al formar parte de la comunidad -y como tal poseían propiedades, pagaban las contribuciones dentro del formato de responsabilidad ciudadana- por lo que en algunos casos eran presuntos implica-

\footnotetext{
${ }^{41}$ Hemos mantenido los mismos campos informativos y sus denominaciones según el documento original.

${ }^{42}$ Lovaton, David - Márquez, Jaime - Ardito, Wilfredo - Montoya, Iván, Justicia de Paz. El otro Poder Judicial (Instituto de Defensa Legal, 1999), pp. 249

${ }^{43}$ AJA: legajo 226, pieza 1, f. $12 \mathrm{v}$.
} 
dos en los diferendos. Un caso similar, se advierte en Laonzana, donde algunos jueces estaban involucrados en conflictos por propiedades: "Señor Juez de Primera Instancia:/ Francisco Oxa vecino del pueblo de Laonzana ante US digo: que en la quebrada arriba de Tarapacá, a distancia de menos de una milla abajo del pueblo de mi residencia, poseo una tierras en el pago nominado de cuchillani colindantes con terrenos que poseen Manuel y Mariano Guacte por la parte de abajo; y por la de arriba con tierras de Pedro Vilca, quebrada grande por medio por un costado por el cerro collpacollpa, y por el otro con la ceja del río y el camino principal que conduce de Tarapacá a Laonzana, cuyo terreno se halla cercado y labrado por mi en su mayor parte.l Deseando que mi posesión conste legalmente, ocurro a su integridad para que se sirva ampararme en ella, para el efecto se servirá mandar testigos que declaren al tenor de las preguntas siguientes: $/ 1^{\circ}$ digan si conocen los terrenos arriba mencionados. $/ 2^{\circ}$ diga si es verdad que poseo dicho terreno por el espacio de veinte tres años, teniéndolo sembrado de alfalfa, si contradicción alguna./ Para el efecto se ha de comisionar al juez de paz tercero de la terna que es Manuel Vilca a excusa de que el primero Alejo Cruz y segundo Eugenio Barreda tienen enemistad grave conmigo librando por el efecto el respectivo despacho en lo que a US pido en justicia, otro si digo:/ Que siendo yo de la casta indigenal debo usar de papel del sello sexto, y no habiéndolo notoriamente presento este escrito, en papel del sello quinto para que teniéndose como reintegro se emplee papel común en las actuaciones y en el despacho./ Iquique Septiembre 4 de 1865./ A ruego de Francisco Oxa, Pedro Caballero" 44

Otro caso es el del el juez de paz de Socoroma Fernando Vildoso. El 17 de septiembre de 1858, Manuel Mamani a nombre de su esposa Carmen Flores "indígena” originaria del Distrito de Socoroma entabla querella de despojo judicial ante el juez de primera instancia de Arica, por unos terrenos que Buenaventura Flores le había cedido a su esposa, y que: "el jues de Paz Vildoso, con mas imperio que la misma ley, y con una autoridad sin limite, por nada mas de haber demandada por si de nombre de su esposa Pablo Quintero, la propiedad de dichos terrenos, sin ver a las partes ni sitarlas en la forma que previene el articulo 74 de la ley reglamentaria de los juecez de Paz, ni estenderse el acta que menciona el 75 del mismo reglamento, a mandado, caprichosamente, que no deba cultivar ni disponer de dichos terrenos, por no ser quien deba disfrutar de ellos" ${ }^{35}$.

Tenemos un juez que aprovecha la coyuntura que le proporciona su cargo para su propio beneficio, incluso vulnera la jurisprudencia que norma a los jueces de paz. El juez Vildoso es acusado de atropellos, de realizar tasaciones de propiedades a su antojo; incluso es reemplazado durante el litigio por el juez de Poconchile. Contrariamente, la defensa de Vildoso expone que el terreno lo deseaba para disponerlo a la venta "en cuia virtud les dije sin biolentados ni espojar al uno ni al otro de lo que cada uno abia trabajado, que siguiese y se preparasen a comprarlo, pues trataba por poner en conocimiento del gobierno, y que estubo seguro lo conseguiria este fondo a beneficio del templo que se trabajaban en este pago, quedando cada uno

${ }^{44}$ APT: volumen 75 , sin folio.

${ }^{45}$ AJA: legajo 313, pieza 2, f.1r-f.1v. 
en posecion de lo que tenia" "46. Vildoso, al parecer actuó en favor de la comunidad, al buscar los recursos para la restauración de la iglesia de Socoroma.

Sobre las denominaciones Aguilar y Cisternas (2007) describen categorías en torno a los jueces de paz, los cuales son también consignados como Jueces de Paz Territorial y Juez de Paz habilitado u oficial ${ }^{47}$. De igual modo, existían "jueces de paz accésit", considerado como "jueces de paz accidentales". Al parecer la diferencia era que el Juez accidental correspondía a un juez auxiliar o de reemplazo, sin embargo, no poseían la oficialidad debida al carecer de Juramento ${ }^{48}$. Mientras que el territorial poseía el nombramiento ${ }^{49}$. Un juicio en Livilcar el 5 de marzo de 1873, deja entrever las diferencias entre el juez territorial y el accidental en torno a la elaboración de documentos. En un acto conciliatorio realizado en el Pueblo de Tignamar el 7 de febrero de 1873 Asunta Colque entrega un terreno en el pago de Lluscuma en el punto denominado Irana Corilarune y también higueras a favor de Mariano Colque. Dichos terrenos eran ocupados indebidamente por Bartolomé Bidaurre, quien a través de un recurso se opuso. Sin embargo, Mariano Colque se defendió al desacreditar el documento de oposición: "Es nulo el documento indicado por que es otorgado ante persona que no muestra el carácter de Juez de Paz como se supone y aparece en el, sino que lo era entonces Don Nicolas Arco, y ademas es mucho tambien, porque suponiendo que hubiera sido tal Jues de Paz el tal Tomas Alave este no podria autorizar semejante documento por ser casado con una prima hermana carnal de Bartolomé Vidaurre: Suponiendo tambien que hubiese Jues de $P a z$ assidental [?] o secante, an tampoco podia autorizar dicho documento, sin que el Juez propietario por impedimiento legal no le hubiera pasado la correspondiente vista que en tal caso solo podria entonces autorizar el documento aludido. Si Tomas Alave no fue Juez de Paz cuando autorizo el espresado documento, es claro que este no tuvo facultad no fue competente para autorizar el acto que aparece practicado ante el; y por esto debe someterse a juicio al dicho Alave. Si el Juez de Paz propietario Don Nicolas Arco que lo fue entonces no tuvo impedimietno legal como lo probase es evidente que claro como la luz del medio dia que la autorización o el auto practicado ante le preindicado Tomas Alave es nulo de hecho y de derecho como lo tengo expuesto" 50

Se advierte que el juez de paz territorial también es denominado como Juez Propio, mientras que el juez accidental era conocido como "juez secante". Este último a pesar que podía elaborar escritos, era un subordinado del juez de paz

${ }^{46}$ AJA, legajo 313, pieza 2, f.1r -f.1v.

${ }^{47}$ Era común que el Juez de Primera Instancia no conociera al Juez de Paz subordinado, por lo que, al envío de algún recurso se refiriera a él como al Juez de Paz habilitado del pueblo.

${ }^{48}$ AJA, legajo 327, Pieza 3, f19v. En una petición para delimitar un deslindes en una Hacienda en el valle de Lluta, en el pago de Caghilana o Siasacapa, el comunero Manuel Lozano envío el siguiente recurso: En arica marzo 10 de 1871 Manuel Lozano envio otro escrito al juez de 1 instancia solicitando que asista al apercibimiento del deslindes a ejecutarse el dia 11 [sabado?] porque el juez de paz comisionado esta ausente y los accidentales no han prestado juramento. Siendo esta situación muy incoveniente y perjuciosa haci su persona (f.3r.) De ese modo, queda claro que los jueces accidentales eran auxiliares del juez de paz. Al ausentarse éste, se invalidaba su accionar, pues carecían de la legitimidad del juramento.

${ }^{49}$ ADT: “Corte Superior de Justicia, Causas civiles”, legajo 53, cuaderno 1624.

${ }^{50}$ AJA: legajo 292, pieza 6, f.11r. 
territorial, ya que requería de su aprobación ${ }^{51}$. Entre los jueces a nivel local, existe una relación burocrática subalterna, participando de la estructura jurídica nacional, aun cuando son todos comuneros de un mismo poblado.

Pero los conflictos entre jueces y comuneros no fue la única tónica. Existieron casos donde los jueces de paz entablaron serias disputas con altas autoridades como el gobernador, lo que significó que se reevaluaran las elecciones de autoridades de acuerdo a criterios de garantizar la convivencia entre los pobladores, para que se ajustaran todos a derecho y no trasgredieran la normativa republicana peruana. Cada vez que los jueces, los comuneros, los tenientes, alcaldes y los gobernadores apelaban a las disposiciones legales y ejercían sus derechos jurídicos, estaban profundizando los compromisos con una ciudadanía política que se construía en la periferia del Estado. A saber: "Señor Coronel Sub Prefecto/ El ciudadano Pablo Cavesas Jues de pás del pueblo de Sivaya, ante VS. con el más profundo respeto dise: que no siéndole posible sufrir por más tiempo los hechos y atentados del Governador de aquel Distrito Don Manuel Ilaja, le és forsoso en representación de sus derechos informar a VS. de los hechos siguientes:/ En las últimas elecciones desgraciadamente me elijieron Jues de pás, y sin embargo de haber hecho presente en la mesa permanente no podía ser tal, en rasón de que no pagaba contribución ninguna al estado, fui electo, y el Señor Presidente prosedió a recibirme./ Practicada mi resepción, el Governador Ilaja, asegurando que VS. le habia dicho no haber dado orden para que me resibiese, principió a conbocar a los de su amaño para que no me ovedeciesen, haciéndoles entender que él mandaba y se habia de cumplir precisamente, y cuyo aserto Señor Coronel, probaría (a) su tiempo con testigos de esepreción, en cuya casa a mi personalmente me dijo, no me reconocía por tal Jues, y que él mandaba no se me reconosiese./ El día martes último de carnabales, reunido Ilaja con muchos en la plaza pública hiso se enarbolase una vandera negra y en ella retratada una calavera, sin más objeto que insultar directamente mi persona y autoridad que represento; permitiendo además, se diesen alli bastantes tiros de pistola y dobles de campanas; pues aun cuando pudo haber sofocado todos estos insultos, supuesto que a él le está encomendado el orden público, en obsequio de sus atribuciones, por el contrario los autorisaba, y dió lugar a toda clase de desórdenes y que hubiesen fuertes choques entre algunos individuos de los que (como es de esperarse) resultaron funestas consecuencias, hasta el estremo de que por poco no susedió una muerte. Con tal conducta que ha observado el Governador Ilaja, ¿qué concepto se podría formar de él? ¿podrán los habitantes de aquel miserable distrito disfrutar de pás y tranquilidad, siendo su Jefe el que fulmina la discordia? ¡Esto es imposible! y lo que importa a VS. Señor Coronel Subprefecto, es proveer oportunamente el remedio antes que los males se hagan más trascendentales" 52 .

Un dato no menor lo constituye la participación electoral en la zona, donde la ritualidad cívica de los comicios, congregando a toda la membresía nacional peruana, de acuerdo a la ley de elecciones de 1867, permitió que mediante esta vía los pobladores andinos asumieran cargos de representación popular, asumiendo

\footnotetext{
${ }^{51}$ Aguilar, Julio - Cisternas, Priscilla, Tierra y Agua en el Perú Sur Andino: Conflictos y Estrategias de Resolución en las Comunidades Indígenas 1830-1880 (Tesis para optar al grado de Profesor de Historia y Geografía, UTA, 2007).

${ }^{52} \mathrm{AJI}$, legajo 1557, pieza 3, 1849.
} 
la política al interior de la comunidad. En tal sentido, en Sibaya se registraron los siguientes resultados: "Iquique, febrero 5 de 1876/ Al Gobernador del Distrito de Sibaya:/ El fiscal de este distrito en vista del oficio fecha 18 de diciembre último, ha expedido el dictamen siguiente: 'Señor Prefecto = La ley orgánica de municipalidades previene que los miembros de los Consejos de Distrito, a excepción de los dos sindicos, que se nombran por la junta directiva del Consejo Provincial, serán elegidos por los ciudadanos al mismo tiempo y en la misma forma que se elijan los colegios electorales, y como por el oficio anterior se viene en conocimiento que en el Distrito de Sibaya, se ha practicado la elección de su consejo sujetándose al artículo 138 de dicha ley, cuando ha debido ser según el articulo 122 de sólo los que debian reemplazar a la mitad de los concejales salientes, quedará absuelta la consulta que hace por dicho oficio al Gobernador de aquel Distrito, con las indicaciones antes dichas y con la prevención, de que la elección ha de hacerse por los ciudadanos que estén en [...] posesión del derecho de sufragio, y en la misma forma que se elijan los colegios electorales, como lo establece el citado artículo 22, no teniendo ya aplicación el 138 que fue transitorio y que debe suponer el consultante como si ya no existiera, y debiendo hacerse dicha elección lo más pronto posible.- Iquique enero 27 de $1876=$ S.P. Roldán'. Se trascribe a US para su inteligencia y para que norme sus procedimientos a las prescripciones legales citadas en el anterior dictamen fiscal./ Dios Guarde a US." 53 .

Siguiendo a Agulhon ${ }^{54}$, el sufragio se constituye como un factor de educación y politización de la sociedad. Para las comunidades disponer del derecho a voto y utilizarlo es servirse de él, aprendiendo de igual modo a debatir los asuntos públicos regionales y nacionales; en definitiva, hacer política ${ }^{55}$. Las condicionantes de la politización se enmarcan en las estructuras que la república liberal proclama, la cual mediante mecanismos como el voto o la articulación de la justicia pública en el seno comunitario, generan que la política se desplace a la aldea y se convierta paulatinamente en una dimensión cardinal de la vida local de los pobladores andinos durante el siglo XIX ${ }^{56}$.

\section{Ciudadanía política y comunidad. Comentarios finales.}

Por imitación, por contactos repetidos, por aproximaciones intersociales o por impregnación, la política irriga e inunda en infinidad de sentidos la estructura interna de la comunidad ${ }^{57}$. Entre los pequeños terratenientes (que vive con frecuencia en el pueblo), el médico (que a menudo es capaz de atender gratis a los pobres), o el abogado (defensor de las comunidades), los obreros de los minerales de plata en Huantajaya, de las calicheras, de las guaneras de las islas chinchas y el

${ }^{53} \mathrm{APT}$, fojas 578-579.

${ }_{54}^{4}$ Agulhon, Maurice, La République au village. Les populations du Var de las Révolution à la IIa République (Seuil, 1979).

${ }^{55}$ Ibíd.; DéLoye, Yves, Sociología histórica de lo político (Santiago, LOM Ediciones, 2004).

${ }^{56}$ AGULHON, Maurice, 1848, le suffrage universal et la politisation des campgnes fracasesen Histoire vagabonde (Paris, Gallimard, 1996).

${ }^{57}$ DéLoYe, Yves, Sociología histórica de lo político (Santiago, LOM Ediciones, 2004). 
campesino hay circulación de ideas e influencias sociales y políticas ${ }^{58}$. Los jueces de paz en cada pueblo fueron "intermedios culturales" en la politización de los Andes de Arica y Tarapacá ${ }^{59}$.

Es una politización por impregnación que acentúa a su vez, los momentos de efervescencia colectiva de la comunidad: como la fiesta patronal o el carnaval, donde se discuten en ocasiones temáticas políticas que generan conflictos entre los miembros del poblado, como se describió en los párrafos precedentes ${ }^{60}$. La asignación de autoridad al juez de paz permitió el establecimiento de redes sociopolíticas y administrativas en el orden burocrático. Los jueces fueron actores intermedios con diversos discursos, actuando en su praxis política como bisagras entre la comunidad y el Estado ${ }^{61}$. A decir de Ruz, el accionar de los jueces se circunscribe a "esferas privadas de poder". Este actor -el juez- investido por el Estado era validado y reconocido localmente; poseía de igual modo "el conocimiento de la comunidad, sus ritos, sus esferas simbólicas, sus demarcaciones y la participación y promoción en estos razonamiento" ${ }^{2}$. Sintetizando lo anterior, las comunidades andinas articularon una praxis política intermedia, lo que significó ciertos "acomodos" o negociaciones en una multiplicidad de aristas ${ }^{63}$.

El camino recorrido por las comunidades andinas durante el siglo XIX se circunscribe a diversas modalidades de prácticas sociales e identitarias, donde la heterogeneidad de las situaciones políticas y culturales describen varios formatos para responder al proyecto liberal y republicano, asumiendo posturas evidentemente contradictorias, ya sea al incorporar las regalías fundadas en la ciudadanía o al apelar al viejo discurso colonial para que fueran reconocidos sus derechos y costumbres sobre las tierras. La participación política a nivel local que ya se venía perfilando desde finales del siglo XVIII, según lo propuesto por Guarisco ${ }^{64}$, al fundamentar que las organizaciones políticas indígenas en el Perú, conocidas como cabildos, no solamente fueron las instancias más pequeñas de la administración colonial, sino que constituyeron instancias políticas significativas para los comuneros, gozando incluso en algunos casos de autonomía.

${ }^{58}$ Ibíd.

${ }^{59}$ Díaz Araya, Alberto, Chilenización y comunidad andina. Educación, reclutamiento militar y articulaciones en Putre. 1883-1929 (Tesis de Magíster en Antropología Social, Instituto de Investigaciones Arqueológicas y Museo R. P. Gustavo Le Paige, Universidad Católica del Norte, San Pedro de Atacama, 2006).

${ }^{60}$ Déloye, Yves, Sociología, cit. (n. 57).

${ }^{61}$ Díaz Araya, Alberto, Chilenización y comunidad andina. Educación, reclutamiento militar y articulaciones en Putre. 1883-1929 (Tesis de Magíster en Antropología Social, Instituto de Investigaciones Arqueológicas y Museo R. P. Gustavo Le Paige, Universidad Católica del Norte, San Pedro de Atacama, 2006).

${ }^{62}$ Ruz, Rodrigo, Escrituras, olvido y memoria. Titulos de propiedad, olvido y prácticas en la tierra aymara. Tarapacá, Siglo XIX/XX, en Revista Diálogo Andino, 26 (2005), p. 101.

${ }^{63}$ Aljovín de LosADA, Cristóbal, Poderes locales en la primera mitad del siglo XIX, en Histórica, 21 (Lima, Pontificia Universidad Católica del Perú, 1997) 1. Véase también: Ruz, Rodrigo, Escrituras, olvido y memoria. Títulos de propiedad, olvido y prácticas en la tierra aymara. Tarapacá, Siglo XIX/XX, en Revista Diálogo Andino, 26 (2005).

${ }^{64}$ Guarisco, Claudia, Etnicidad y ciudadanía en México y Perú(1770-1850), en Documentos de Investigación del Colegio Mexiquense, 84 (México, 2004). 
Kymlicka $^{65}$ enfatiza que las comunidades se mueven bajos dos dimensiones asociadas a la participación ciudadanía. Por un lado, la dimensión práctica - política donde se interpreta el acto ciudadano como una forma de participación activa en las cosas públicas; esta pueden ser, por ejemplo, el acto de inscribir tierras, asistir y demandar establecimientos educacionales, aprobar las normas de salud e higiene diseñadas desde un plan estatal, participar en elecciones, inscribirse en registro de identificación, entre otras. Por tal motivo, la participación política exige sacrificio, una abnegación individual para beneficio colectivo. La segunda dimensión guarda relación con la exigencia de las minorías; supone al mismo tiempo, el reconocimiento y las garantías públicas de sus derechos y deberes como sujetos privados.

La identidad en este escenario histórico, debe ser comprendida como una representación que poseen los diferentes sujetos (indígenas andinos para el caso estudiado) en el espacio social y de las múltiples relaciones con otros sujetos que ocupan de igual forma la misma posición, o a su vez, posiciones diferenciadas en el mismo espacio, "en cuanto representación de un sí mismo o de un nosotros socialmente situados, la identidad es esencialmente distintiva, relativamente

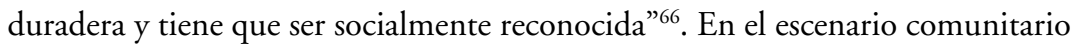
la ciudadanía llegó a ser un recurso utilizado por los indígenas andinos ${ }^{67}$. La ciudadanía en términos de su praxis comunitaria, se debe más a los procesos locales de adopción, que no abandonan por tanto sus intereses o su pertenencia local, que a una acción concertada del Estado. La comunidad local, al ejercer los derechos y deberes ciudadanos dentro de los términos de una praxis política como lo constituye la participación en la administración de la justicia, genera una representación performativa en torno a cierta identidad ciudadana ${ }^{68}$.

${ }^{65}$ Kymlicka, Will, Las fuentes del Nacionalismo, en McKim, Robert - MacMahan, Jeff, La moral de los nacionalismo, I: Orígenes, psicología y dilemas de parcialidad de los sentimientos nacionales (Barcelona, Gedisa, 2003), p. 88.

${ }^{66}$ GIMÉNEZ, Gilberto, Modernización, cultura e identidades tradicionales en México, en Revista Mexicana de Sociología, 4 (México, 1994), p. 261. Para Giménez la noción de identidad étnica apela a una especificación social basada en la autopercepción subjetiva que tienen de si mismo los actores llamados grupos étnicos. Se trata de unidades social y culturalmente diferenciadas, constituidas como grupos involuntarios que se caracterizan por formas tradicionales y no emergentes de solidaridad social, y que interactúan en situación de minorías dentro de sociedades más amplias y envolventes, Giménez, Gilberto Modernización, cultura e identidades tradicionales en México, Revista mexicana de Sociología, no 4, México, 1994, pp. 267. A su vez, cuando existe un refuerzo permanente en la comunidad debido a intereses o prácticas políticas, es posible, siguiendo a BRASS, Paul, Ethnicity and Nationalism. Theory and Comparison (New Delhi, Sage Publications, 1999), p. 19, que bajo ciertas circunstancias (como es el caso de la chilenización en la zona andina, las comunidades étnicas se transformen en nacionales.

${ }^{67}$ Andaur, Carolina, Descubrimiento y conquista del ejercicio ciudadano. Las poblaciones andinas de Tarapacá a mediados del siglo XIX, en Los Andes entre el tributo y la Nación: las comunidades aymaras durante el siglo XIX (Iquique, Universidad Bolivariana, 2005).

${ }^{68}$ HOMI, Bhabha, El lugar de la cultura (Buenos Aires, Manantial, 2002), p. 19, expone que el compromiso cultural, ya sea antagónico o afiliativo, se producen performativamente. La representación de la diferencia no debe ser leída apresuradamente como el reflejo de rasgos étnicos o culturales ya dados en las tablas fijas de la tradición. La articulación social de la diferencia, desde la perspectiva de la minoría, es una compleja negociación en marcha que busca autorizar 


\section{BiBLIOGRAFÍA}

Archivos

Archivo Departamental de Tacna (ADT), Documentos republicanos anteriores a 1880, Corte Superior de Justicia, Perú.

Archivo General de la Nación, Perú (AGN), Ministerio de Justicia, Corte de Justicia Superior, Moquegua, 1857-1875, Perú.

Archivo General de la Nación, Perú (AGN), Ministerio de Justicia, Prefectura de Tarapacá, Perú.

Archivo Nacional de Chile, Archivo de la Prefectura de Tarapacá (APT), Chile.

Archivo Nacional de Chile, Archivos Judiciales de Arica (AJA), Chile.

Archivo Nacional de Chile, Archivos Judiciales de Iquique (AJI), Chile.

Biblioteca Nacional del Perú (BNP).

\section{Literatura}

Aguilar, Julio - Cisternas, Priscilla, Tierra y Agua en el Perú Sur Andino: Conflictos y Estrategias de Resolución en las Comunidades Indígenas 1830-1880 (Tesis para optar al grado de Profesor de Historia y Geografía, UTA, 2007).

AGUlHON, Maurice, 1848, le suffrage universal et la politisation des campgnes fracasesen Histoire vagabonde (Paris, Gallimard, 1996).

Agulhon, Maurice, La République au village. Les populations du Var de las Révolution à la II République (Seuil, 1979).

Aljovín de Losada, Cristóbal, Poderes locales en la primera mitad del siglo XIX, en Histórica, 21 (Lima, Pontificia Universidad Católica del Perú, 1997) 1.

Aljovín de Losada, Cristóbal, Prácticas políticas y formación de ciudadanía, en ChilePerú, Perú-Chile: 1820-1920. Desarrollos politicos, económicos y culturales (Valparaíso, Ediciones Universitarias de Valparaíso, 2005).

Aljovín de Losada, Cristóbal, Sufragio y participación política. Perú: 1808-1896, en Aljovín de Losada, Cristóbal - López, Sinesio (editores), Historia de las elecciones en el Perú (Lima, Instituto de Estudios Peruanos, 2005).

Andaur, Carolina, Descubrimiento y conquista del ejercicio ciudadano. Las poblaciones andinas de Tarapacá a mediados del siglo XIX, en Los Andes entre el tributo y la Nación: las comunidades aymaras durante el siglo XIX (Iquique, Universidad Bolivariana, 2005).

ARdito, Wilfredo, Justicia de paz en el Perú, en Allpanchis. Instituto de Pastoral Andina, año 34, $\mathrm{N}^{\circ} 60$ Cuzco, 2002).

los híbridos culturales que emergen en momentos de transformación histórica. El derecho a significar desde la periferia del poder autorizado y el privilegio no depende de la persistencia de la tradición; recurre al poder de la tradición para reinscribirse mediante las condiciones de contingencia y contradictoriedad que están al servicio de las vidas de los que están en la minoría [...] los compromisos fronterizos de la diferencia cultural pueden ser tanto consensuales como conflictuales; pueden confundir nuestras definiciones de la tradición y la modernidad; realinear los límites habituales entre lo privado y lo público, lo alto y lo bajo, y desafiar las expectativas normativas de desarrollo y progreso. Por su parte, Tilly, Charles, Citizenship, Identity and Social History, en Internacional Review of Social History, Supplements (Melbourne, The Press Syndicate of the University of Cambridge, 1996), pp. 227, señala que la identidad ciudadana se refiere a la representación colectiva de esa experiencia conjunta que, a su turno, procura un sentimiento de unidad. 
Brass, Paul, Ethnicity and Nationalism. Theory and Comparison (New Delhi, Sage Publications, 1999).

Castro, Luis - Figueroa, Carolina, Continuidad y cambio: la institución del cacicazgo en Tarapacá (norte de Chile) desde el lapso tardo-colonia al período republicano (ms. 2005).

Chiaramonti, Gabriella, A propósito del debate Herrera-Gálvez de 1849: breves reflexiones sobre el sufragio de los indios analfabetos, en ALJOvín DE LOSADA, Cristóbal - LÓPEZ, Sinesio (editores), Historia de las elecciones en el Perú (Lima, Instituto de Estudios Peruanos, 2005).

Contreras, Carlos - Marcos Cueto, Historia del Perú contemporáneo (Lima, Instituto de Estudios Peruanos, 2000).

Contreras, Carlos, Estado republicano y tributo indígena en la sierra central en la post-Independencia, en Revista Histórica, 13 (Lima, Pontificia Universidad Católica del Perú, 1989).

Del Castillo, Miguel - León, Angélica, Las Prefecturas en el Perú (1823-1919). Catálogo de Memorias de gobierno de Prefectos y Subprefectos, en Revista del Archivo General de la Nación, 16 (2a época, Lima, 1997).

Déloye, Yves, Sociología histórica de lo político (Santiago, LOM Ediciones, 2004).

Díaz AraYA, Alberto, Chilenización y comunidad andina. Educación, reclutamiento militar y articulaciones en Putre. 1883-1929 (Tesis de Magíster en Antropología Social, Instituto de Investigaciones Arqueológicas y Museo R. P. Gustavo Le Paige, Universidad Católica del Norte, San Pedro de Atacama, 2006).

DíAz, Alberto De la cordillera al mar. Una reflexión histórica sobre los aymaras chilenos $y$ los mercados regionales, en Boletín International Fellowship Program. Leadership for Social Justice Institute, 2 (2004) 8.

DUNAWAY, Nicole, Crisis del cacicazgo, participación politica indígena y estado colonial en los corregimientos de Arica y Tarapacá, 1780-1815 (Tesis para optar al Grado de Magíster en Historia, Mención en Etnohistoria, Facultad de Filosofía y Humanidades, Escuela de Postgrado, Universidad de Chile, 2003).

Foucault, Michel, Vigilar y castigar (México, Siglo XXI Editores, 1997).

Giménez, Gilberto, Modernización, cultura e identidades tradicionales en México, en Revista Mexicana de Sociología, 4 (México, 1994).

GonZÁlez, Héctor, Los aymaras de la región de Tarapacá y el periodo republicano temprano (1821-1879) (Documento de Trabajo de la Comisión de Verdad Histórica y nuevo trato, Subgrupo Pueblo Aymara, Santiago, 2002).

Guarisco, Claudia, Etnicidad y ciudadanía en México y Perú (1770-1850), en Documentos de Investigación del Colegio Mexiquense, 84 (México, 2004).

Homi, Bhabha, El lugar de la cultura (Buenos Aires, Manantial, 2002).

Kymlicka, Will, Las fuentes del Nacionalismo, en McKim, Robert - MacMahan, Jeff, La moral de los nacionalismo, I: Orígenes, psicología y dilemas de parcialidad de los sentimientos nacionales (Barcelona, Gedisa, 2003).

Lovaton, David - Marquez, Jaime - ARdito, Wilfredo - Montoya, Iván, Justicia de Paz. El otro Poder Judicial (Instituto de Defensa Legal, 1999).

Martínez, Gabriel , El sistema de los Uywiris en Isluga, en Espacio y Pensamiento (La Paz, Hisbol, 1989).

NúNẼE, Francisco La participación electoral indígena bajo la Constitución de Cádiz (1812-1814), en Aljovín de Losada, Cristóbal - López, Sinesio (editores), Historia de las elecciones en el Perú (Lima, Instituto de Estudios Peruanos, 2005). 
O'Phelan, Scarlet, Kurakas sin sucesiones. Del cacique al alcalde de indios. Perú y Bolivia 1750-1835 (Cuzco, CBC, 1997).

RuZ, Rodrigo, Escrituras, olvido y memoria. Títulos de propiedad, olvido y prácticas en la tierra aymara. Tarapacá, Siglo XIX/XX, en Revista Diálogo Andino, 26 (2005).

Thurner, Mark, Los indios y la repúblicas entre 1830-1880, en Historia de América Andina, Creación de las repúblicas y formación de la nación (Quito, Universidad Andina Simón Bolívar, 2003), V.

Thurner, Mark, Republicanos y la comunidad de peruanos: Comunidades políticas inimaginadas en el Perú postcolonial, en Revista Histórica, 20 (Lima, Pontificia Universidad Católica del Perú, 1996) 1.

Tilly, Charles, Citizenship, Identity and Social History, en Internacional Review of Social History, Supplements (Melbourne, The Press Syndicate of the University of Cambridge, 1996).

Urquieta, Débora, De campesino a ciudadano. Aproximación jurídica (Cusco, Centro Bartolomé de Las Casas, 1993).

Van Kessel, Juan, Cuando arde el tiempo sagrado (La Paz, Hisbol, 1992); Díaz Araya, Alberto, Fiesta y fútbol entre los Aymaras del norte de Chile: el caso de Sotoca y Chiapa, en Boletín International Fellowship Program - Leadership for Social Justice Institute, 13 (2006).

Walker, Charles, De Tupác Amaru a Gamarra: Cusco y la formación del Perú Republicano 1780-1840 (Cusco, Centro de Estudios Regionales Andinos Bartolomé de Las Casas, 1999). 